\title{
HEALTH-RELATED QUALITY OF LIFE OF PREGNANT WOMEN WITH HEARTBURN AND REGURGITATION
}

\author{
Valesca DALL'ALBA ${ }^{1,2,3}$, Sidia Maria CALLEGARI-JACQUES ${ }^{4}$, Cláudio KRAHE ${ }^{5}$, \\ Juliana Paula BRUCH ${ }^{1}$, Bruna Cherubini ALVES ${ }^{1}$ and Sérgio Gabriel Silva de BARROS ${ }^{1,6}$
}

\begin{abstract}
Background - Heartburn and regurgitation frequently occur in the third trimester of pregnancy, but their impact on quality of life has not been thoroughly investigated. Objective - To measure health-related quality of life of third-trimester pregnant women with heartburn and regurgitation. Methods - Data on obstetric history, heartburn and regurgitation frequency and intensity, history of heartburn and regurgitation and health-related quality of life were collected of 82 third-trimester pregnant women. Results - Sixty-two (76\%) women had heartburn, and 58 (71\%), regurgitation; 20 were asymptomatic. Mean gestational age was $33.8 \pm 3.7$ weeks; $35(43 \%)$ women had a family history of heartburn and/or regurgitation, and $57(70 \%)$ were asymptomatic before pregnancy. The following quality of life concepts were significantly reduced: physical problems and social functioning for heartburn; physical problems and emotional functioning for regurgitation. There was agreement between heartburn in present and previous pregnancies. Conclusion - Heartburn and/or regurgitation affected health-related quality of life of third trimester pregnant women. HEADINGS - Heartburn. Gastroesophageal reflux. Pregnancy. Quality of life.
\end{abstract}

\section{INTRODUCTION}

The importance of perceptions about health and health-related quality of life (HRQoL), as well as of the impact of both disease and treatment, has been widely acknowledged in clinical and epidemiological studies $^{(9)}$. The generic description of differences in health-related quality of life for a single disease and their comparison with differences for other diseases may demonstrate its importance for an individual in a given community. HRQoL parameters are therefore necessary to provide guidelines for more adequate health policy decisions ${ }^{(6)}$.

Although other generic instruments are available - such as the SIP (Sickness Impact Profile), NHP (Nottingham Health Profile), QWB (Quality of Well Being Scale), PGWB (Psychological General Well-Being Index) - the SF-36 (Medical Outcomes Study 36-Item Short-Form Health Survey) is still the most used, particularly in gastroenterology, to quantify differences between patients with gastrointestinal diseases and controls ${ }^{(21)}$. The SF-36 has been studied in many populations with specific diseases and is considered an appropriate tool to describe health and HRQoL during pregnancy.

According to The Montreal Consensus, Gastro- esophageal Reflux Disease (GERD) is a condition that develops when the reflux of stomach contents causes troublesome symptoms and/or complications. The characteristic symptoms of GERD, recognized by the Consensus are heartburn and regurgitation ${ }^{(18)}$.

It has been previously reported that GERD is common during pregnancy, and the prevalence reaches around $30 \%-80 \%$ of pregnant women ${ }^{(13,16)}$ Heartburn and regurgitation are the most prevalent symptoms of GERD, that often occur in pregnancy, becoming worse as pregnancy advances, and decreasing following the delivery ${ }^{(3,13,16)}$. However, their impact on health-related quality of life has not yet been sufficiently studied.

The pathogenesis of GERD in pregnancy is multifactorial. Some combined factors play an important role in the etiology of GERD in pregnancy: decreased lower esophageal sphincter pressure and alteration in gastrointestinal transit due to hormone changes, and increased intragastric and intra-abdominal pressure secondary to the enlarged gravid uterus ${ }^{(1,13)}$.

The objective of this study was evaluate the HRQoL during pregnancy in the presence of symptoms of GERD, such as heartburn and regurgitation. The hypothesis was that pregnant women with symptoms have a worse quality of life than those without symptoms.

Declared conflict of interest of all authors: none

Disclosure of funding: no funding received

Post Graduate Program - Ciências em Gastroenterologia e Hepatologia, School of Medicine, Universidade Federal do Rio Grande do Sul (UFRGS): 2 Department of Nutrition School of Medicine, UFRGS. ${ }^{3}$ Nutrition Division, Hospital de Clínicas de Porto Alegre, UFRGS. 4 Department of Statistics and Genetics, UFRGS. 5 Department of Obstetrics and Gynecology, School of Medicine, Pontifícia Universidade Católica do Rio Grande do Sul; ${ }^{6}$ Gastroenterology Division, Hospital de Clínicas de Porto Alegre, UFRGS. Porto Alegre, RS, Brasi

Correspondence: Prof. a Valesca Dall'Alba. R. Ramiro Barcelos, 2400 - CEP: 90035-003 - Porto Alegre, RS, Brasil. E-mail: valba@hcpa.ufrgs.br 


\section{METHODS}

Sample size calculation for this case-control study was based on mean SF-36 scores according to data published by Revicki et al. ${ }^{(17)}$

Scores to quantify patients' general HRQoL were obtained by means of the Portuguese version of the SF-36 (Medical Outcomes Study 36- Item Short-Form Health Survey) generic questionnaire, validated by Ciconelli et al. ${ }^{(6)}$. The questionnaire is composed of 36 questions that assess 8 health concepts: physical functioning, role function as limited by physical problems, pain, general health, vitality, social functioning, role function as limited by emotional problems, and mental health. Scores range from zero to 100; zero corresponds to the lowest general health status, and 100, to the highest ${ }^{(20)}$.

All pregnant women at 28 or more weeks of gestation consecutively seen at a low-risk prenatal outpatient service of Hospital São Lucas, Pontifícia Universidade Católica do Rio Grande do Sul, were invited to participate in the study. They answered a questionnaire about symptoms and symptom intensity, age, ethnicity, obstetric history, medication, and anthropometric measurements.

In this cross-sectional study eighty-two third-trimester pregnant women were studied: 62 had heartburn and/or regurgitation (symptomatic group), and 20 were asymptomatic. Patients with diabetes, hypertension or other chronic diseases, as well as those that were taking any medication for heartburn and/or regurgitation, were excluded from the study.

The following statistical tests were used for data analysis: Student $t$ test for two independent samples, and ANOVA for more than two samples, followed by Dunnett test for quantitative variables; nonparametric Wilcoxon-Mann-Whitney test for quantitative variables that did not meet requirements for the $t$ test; Fisher exact test for categorical variables that did not meet requirements for the chi-square test; kappa coefficient and corresponding confidence interval to assess agreement between symptoms of the same patient on different occasions. Significance was established at $P<0.05$.

\section{RESULTS}

Mean age ( \pm standard deviation) was $26 \pm 6.42$ years. Mean pregestational weight and height were, respectively, $60.0 \pm 9.5 \mathrm{~kg}$ and $1.6 \pm 0.1 \mathrm{~m}$. Mean pregestational body mass index (BMI) was $23.2 \pm 3.4 \mathrm{~kg} / \mathrm{m}^{2}$. Mean weight gain was $12.2 \pm 2.6 \mathrm{~kg}$, and mean gestational age was $33.8 \pm 3.7$ weeks. Sixty-two $(76 \%)$ women reported heartburn, and 58 (71\%) regurgitation. The level of education for the group under study was: $17(21 \%)$ - less than primary school; 14 $(17 \%)$ - primary school; $13(16 \%)$ less than secondary school; $29(35 \%)$ - secondary school; and $1(1 \%)$ - at least some college education. Mean time to fill out the self-administered questionnaire was $11.5 \pm 3.7$ minutes. When these variables were analyzed by symptom, there was not statistically difference in age $(P=0.890)$, pregestational BMI $(P=0.391)$, current BMI $(P=0.167)$, weight gain $(P=0.161)$, and level of education $(P=0.405)$ in women with and without heartburn. When analyzed by regurgitation, it was also not found any statistically difference ( $P \geq 0.05$ for all).

Thirty-five $(43 \%)$ pregnant women reported a family history of heartburn and/or regurgitation; 25 (31\%) had pregestational heartburn, and $57(70 \%)$ reported not having these symptoms when not pregnant. Among multiparous women, $54(65 \%)$ had already had heartburn in previous pregnancies, and there was agreement between heartburn in third trimester and in previous pregnancies (kappa $=$ $0.33 ; P=0.005 ; 95 \%$ CI, 0.05-0.56). No significant correlation was found between pregestational heartburn and heartburn in present pregnancy (kappa $=0.09 ; P=0.121$; $95 \% \mathrm{CI},-0,31$ to $-0,11)$. Mean weight of pregnant women with heartburn $(73.7 \pm 11.0 \mathrm{~kg})$ was significantly greater than that of asymptomatic patients $(67.8 \pm 10.4 \mathrm{~kg})$ $(P=0.037)$, but no significant difference in weight gain was found between the two groups (pregnant women with heartburn $=12.7 \pm 5.0 \mathrm{~kg}$; asymptomatic pregnant women $=10.8 \pm 5.2 \mathrm{~kg} ; P=0.161)$.

No pregnant women reported alcohol drinking during pregnancy, but six (7\%) smoked, and $22(27 \%)$ were ex-smokers. Forty-five (55\%) patients took medication; the drug most frequently used was ferrous sulphate. These and other general characteristics of all pregnant women are shown in Table 1.

Scores of HRQoL concepts were lower for pregnant women with heartburn and/or regurgitation than for controls. Two health concepts were significantly affected for women with heartburn: physical problems $(P=0.009)$ and social functioning $(P=0.020)$, shown in Table 2 . For women with regurgitation, two aspects were significantly affected: physical problems $(P=0.004)$; and emotional problems $(P=0.002)$, stated in Table 3.

More than $51 \%$ of the symptomatic pregnant women had three or more heartburn episodes per week. The scores of HRQoL between pregnant women with heartburn twice or more times a week and less than twice a week are shown in Table 4.

TABLE 1. Symptoms and general characteristics of pregnant women in the study

\begin{tabular}{lccc}
\hline & $\mathbf{n}$ & Percentage & $95 \% \mathbf{C I}$ \\
\hline $\begin{array}{l}\text { Heartburn in present } \\
\text { pregnancy }\end{array}$ & $62 / 82$ & 75.6 & $64.9-84.4$ \\
$\begin{array}{l}\text { Regurgitation in } \\
\text { present pregnancy }\end{array}$ & $58 / 82$ & 70.7 & $59.6-80.3$ \\
$\begin{array}{l}\text { Pregestational } \\
\text { heartburn }\end{array}$ & $25 / 82$ & 30.5 & $20.8-41.6$ \\
$\begin{array}{l}\text { Heartburn in previous } \\
\text { pregnancies }\end{array}$ & $35 / 54$ & 64.8 & $50.6-77.3$ \\
$\begin{array}{l}\text { Family history of } \\
\text { GERD }\end{array}$ & $35 / 82$ & 42.7 & $31.8-54.1$ \\
$\begin{array}{l}\text { Smoking } \\
\text { Medication }\end{array}$ & $6 / 82$ & 7.3 & $2.7-15.2$ \\
* student $t$ test; & $45 / 82$ & 54.9 & $43.5-65.9$ \\
\hline
\end{tabular}

* student $t$ test; $\mathrm{CI}$ : confidence interval 
TABLE 2. Means for each health-related quality of life (QOL) concept - comparison of third trimester pregnant women with and without heartburn

\begin{tabular}{|c|c|c|c|c|c|}
\hline \multirow{2}{*}{ QOL concept } & \multicolumn{2}{|c|}{ Heartburn } & \multirow{2}{*}{ Dif. } & \multirow{2}{*}{$95 \% \mathrm{CI}$} & \multirow{2}{*}{$P^{*}$} \\
\hline & Yes $(n=62)$ & No $(n=20$ & & & \\
\hline Physical problems & $41.5 \pm 38.7$ & $67.5 \pm 33.5$ & -26.0 & -45.2 to -6.8 & 0.009 \\
\hline Emotional problems & $55.4 \pm 38.1$ & $73.3 \pm 35.2$ & -17.9 & -37.1 to 1.2 & 0.066 \\
\hline Physical functioning & $61.0 \pm 22.5$ & $67.8 \pm 19.8$ & -6.8 & -17.9 to 4.5 & 0.238 \\
\hline Mental health & $70.1 \pm 17.8$ & $74.0 \pm 18.7$ & -3.9 & -13.1 to 5.3 & 0.405 \\
\hline Social functioning & $62.5 \pm 21.3$ & $75.0 \pm 16.9$ & -12.5 & -22.9 to -2.0 & 0.020 \\
\hline Vitality & $54.7 \pm 19.8$ & $64.0 \pm 16.1$ & -9.3 & -19.1 to 0.4 & 0.060 \\
\hline Pain & $57.1 \pm 19.7$ & $60.0 \pm 21.1$ & -2.9 & -13.1 to 7.4 & 0.584 \\
\hline General health & $77.2 \pm 16.3$ & $78.0 \pm 12.7$ & -0.8 & -8.8 to 7.1 & 0.837 \\
\hline Annual change & $57.3 \pm 19.4$ & $65.0 \pm 20.5$ & -7.7 & -17.8 to 2.3 & 0.130 \\
\hline
\end{tabular}

* Student $t$ test; CI: confidence interval; Dif: difference

TABLE 3. Means for each health-related quality of life (QOL) concept - comparison of third trimester pregnant women with and without regurgitation

\begin{tabular}{|c|c|c|c|c|c|}
\hline \multirow{2}{*}{ QOL concept } & \multicolumn{2}{|c|}{ Regurgitation } & \multirow{2}{*}{ Dif. } & \multirow{2}{*}{$95 \% \mathrm{CI}$} & \multirow{2}{*}{$P *$} \\
\hline & Yes $(n=58)$ & No $(n=24)$ & & & \\
\hline Physical problems & $40.1 \pm 37.2$ & $66.7 \pm 37.3$ & -26.6 & -44.6 to 8.6 & 0.004 \\
\hline Emotional problems & $51.7 \pm 37.0$ & $79.2 \pm 33.8$ & -27.5 & -44.9 to 10.0 & 0.002 \\
\hline Physical functioning & $60.8 \pm 23.0$ & $67.3 \pm 18.8$ & -6.5 & -17.1 to 4.1 & 0.224 \\
\hline Mental health & $70.1 \pm 18.9$ & $73.3 \pm 15.7$ & -3.2 & -11.9 to 5.5 & 0.467 \\
\hline Social functioning & $63.0 \pm 22.1$ & $71.8 \pm 16.7$ & -8.8 & -17.7 to 0.2 & 0.056 \\
\hline Vitality & $56.1 \pm 19.9$ & $59.0 \pm 18.0$ & -2.9 & -12.2 to 6.5 & 0.532 \\
\hline Pain & $55.2 \pm 19.5$ & $64.4 \pm 19.9$ & -9.2 & -18.7 to 0.3 & 0.058 \\
\hline General health & $75.9 \pm 16.7$ & $80.9 \pm 11.4$ & -5.0 & -12.4 to 2.5 & 0.189 \\
\hline Annual change & $59.0 \pm 20.2$ & $59.4 \pm 19.2$ & -0.4 & -10.0 to 9.3 & 0.947 \\
\hline
\end{tabular}

* Student $t$ test; CI: confidence interval; Dif: difference

TABLE 4. Means for each health-related quality of life (QOL) concept according to the frequency of heartburn

\begin{tabular}{|c|c|c|c|}
\hline \multirow[b]{2}{*}{ QOL concept } & \multicolumn{2}{|c|}{ Heartburn frequency } & \multirow[b]{2}{*}{$P^{*}$} \\
\hline & $\begin{array}{c}\geq 2 \text { times/ } \\
\text { week }(n=42)\end{array}$ & $\begin{array}{c}<2 \text { times/ } \\
\text { week }(n=40)\end{array}$ & \\
\hline Physical problems & $42.9 \pm 38.4$ & $53.1 \pm 39.3$ & 0.235 \\
\hline Emotional problems & $56.3 \pm 40.0$ & $63.3 \pm 36.0$ & 0.409 \\
\hline Physical functioning & $60.8 \pm 22.4$ & $64.6 \pm 21.6$ & 0.438 \\
\hline Mental health & $71.4 \pm 17.2$ & $70.7 \pm 18.9$ & 0.856 \\
\hline Social functioning & $65.3 \pm 19.0$ & $65.8 \pm 23.0$ & 0.916 \\
\hline Vitality & $56.0 \pm 19.1$ & $58.0 \pm 19.8$ & 0.634 \\
\hline Pain & $57.7 \pm 22.0$ & $58.1 \pm 17.9$ & 0.931 \\
\hline General health & $78.4 \pm 17.0$ & $76.3 \pm 13.7$ & 0.550 \\
\hline Annual change & $60.1 \pm 20.0$ & $58.1 \pm 19.9$ & 0.652 \\
\hline
\end{tabular}

\section{DISCUSSION}

Pregnant women were recruited for the study at a low-risk prenatal outpatient service in an attempt to reduce biases, such as the inclusion of pregnant women with diabetes, hypertension, or any other disease either associated with pregnancy or not.

According to the Brazilian Health Ministry, low maternal schooling (fewer than 5 schooling years) and maternal age in the extremes of the reproductive age group are the risk factors associated with negative obstetric outcomes. Most of the pregnant women in this study were older than 17 and younger than 35 years, and were multiparous. Most of them $(80 \%)$ had finished at least elementary school, and the time that they took to fill out the self-administered SF-36 questionnaire suggested that they could understand it easily.

Our results suggest that both heartburn and regurgitation are highly prevalent and frequent in the third trimester of pregnancy. Other authors have reported high prevalence rates for heartburn in pregnancy ${ }^{(2,11,14-16)}$, but prevalence rates of regurgitation have been less investigated. The high prevalence 
rate for regurgitation found in our sample was similar to the rate for heartburn (one pregnant woman with regurgitation for each 1.6 with heartburn), differently from rates found in the general population, which is one person with regurgitation for each three individuals with heartburn ${ }^{(4)}$. In a cohort study, it was found that $35.3 \%$ of pregnant women during third trimester of pregnancy suffered at least once a week from heartburn and $40.7 \%$ from regurgitation ${ }^{(13)}$. The same study also showed a GERD prevalence of $51.2 \%$ in third trimester of pregnancy. Regurgitation is more prevalent in this period of life, and it seems to affect quality of life more significantly than heartburn.

When our data were analyzed according to the frequency of symptoms of heartburn (two or more times a week), no significant differences in HRQoL were observed. At a later stage, data on patients with symptoms one or more times a week were compared to data on patients with less frequent symptoms; this comparison revealed signs of a negative impact in the quality of life of women in the first group. However, the most significant negative impact of symptoms (heartburn and/or regurgitation) in HRQoL was observed when data on pregnant women with heartburn and/or regurgitation at any frequency were compared to data on those that were asymptomatic. This finding suggests that criteria to diagnose GERD in pregnant women should be different from those used for the general population. It also suggests that even sporadic complaints should be taken into consideration during pregnancy, because one monthly episode of heartburn, depending on its intensity and duration, may be enough to reduce the quality of life of a pregnant woman.

Heartburn in pregnancy does not seem to be associated with the patient's history, differently from what is observed in the general population. However, most pregnant women that had these symptoms in previous pregnancies also reported them for the present pregnancy. These facts are in agreement with studies that suggest that the increase in the levels of progesterone and/or estrogen during pregnancy is the main cause of the decreased pressure of the lower esophageal sphincter ${ }^{(5,7,8,10-12,14,19)}$. These studies suggest that the symptoms studied here are not associated with mechanical factors, such as weight gain, and are not triggered by increased intraabdominal and intragastric pressure.

\section{CONCLUSIONS}

Our study revealed a high prevalence of heartburn and regurgitation among women in the third trimester of pregnancy. Patients with heartburn and/or regurgitation obtained lower scores in several HRQoL concepts than asymptomatic pregnant women. No association was found with pregestational heartburn, but there was agreement between reports of symptoms in present and previous pregnancies.

\section{Ethical standards}

The study was approved by the Ethics Committee of the Hospital de Clínicas de Porto Alegre - UFRGS and PUCRS. All patients who agreed to participate were informed about the research objectives and included after signing the Informed Consent. This was done in accordance with the ethical standards laid down in the 1964 Declaration of Helsinki and its later amendments. The authors declare that they have complete control of all primary data and agree to allow the journal to review the data if requested.

\section{Authors' contributions}

Dall'Alba V: protocol/project development, data collection and management, data analysis, manuscript writing/ editing. Callegari-Jacques SM: data analysis, and interpretation of data. Krahe C: project development, and manuscript writing/editing. Bruch JP: data collection, and data analysis. Alves BC: data collection, and data analysis. Barros SGS: protocol/project development, management, data analysis, manuscript writing/editing.

Dall'Alba V, Callegari-Jacques SM, Krahe C, Bruch JP, Alves BC, Barros SGS. Qualidade de vida em gestantes com pirose e regurgitação. Arq Gastroenterol. 2015,52(2):100-4.

RESUMO - Contexto - A pirose e a regurgitação ocorrem com frequência no terceiro trimestre de gestação, mas o seu impacto na qualidade de vida não foi completamente investigado. Objetivo - Avaliar a qualidade da vida de gestantes do terceiro trimestre com pirose e regurgitação. Métodos - Os dados sobre a história obstétrica, frequência, intensidade e história de pirose e regurgitação, bem como a qualidade de vida foram coletados de 82 mulheres do terceiro trimestre de gestação. Resultados - Sessenta e duas (76\%) mulheres tinham pirose e, 58 (71\%), regurgitação; 20 eram assintomáticas. A idade gestacional média foi de 33,8 \pm 3,7 semanas; 35 (43\%) mulheres tinham história familiar de pirose e/ou regurgitação e 57 (70\%) eram assintomáticos antes da gestação. Os seguintes domínios de qualidade de vida estavam significativamente reduzidos: limitação física e aspectos sociais pela pirose; limitação física e aspectos emocionais pela regurgitação. Houve concordância entre pirose nas gestações atuais e prévias. Conclusão - A pirose e/ou regurgitação afetam a qualidade de vida de gestantes de terceiro trimestre.

DESCRITORES - Azia. Refluxo gastroesofágico. Gravidez. Qualidade de vida. 


\section{REFERENCES}

1. Arantes MR, Fraga FC. Doenças do aparelho digestivo. In: Rezende J. Obstetrícia. $8^{a}$ ed. Rio de Janeiro: Guanabara Koogan; 1998. p. 440-61.

2. Bainbridge ET, Temple JG, Nicholas SP, Newton JR, Boriah V. Symptomatic gastroesophageal reflux in pregnancy. A comparative study of white Europeans and Asians in Birmingham. Br J Clin Prac. 1983;37(2):53-7.

3. Baron TH, Richter JE. Gastroesophageal reflux disease in pregnancy. Gastroenterol Clin North Am. 1992;21(4):777-91.

4. Barros SGS, Lopes AB, Grüber AC. Doença do Refluxo Gastroesofágico: diagnóstico e Conduta Clínica. In: Nader F. Gastroenterologia IV. Pelotas: Ed. Universitária, UFPEL; 2001. p. 33-46.

5. Broussard CN, Richter JE. Treating gastroesophageal reflux during pregnancy and lactation: what are the safest therapy options? Drug Saf. 1998;19(4):325-37.

6. Ciconelli RM, Ferraz MB, Santos W, Meinão I, Quaresma MR. Tradução para a língua portuguesa e validação do questionário genérico de avaliação de qualidade de vida SF-36 (Brasil SF-36). Rev Bras Reumat. 1999;39:143-50.

7. Fisher RS, Roberts GS, Grabowski CJ, Cohen S. Inhibition of lower esophageal sphincter circular muscle by female sex hormones. Am J Physiol 1978; 234(3):243-7.

8. Fisher RS, Roberts GS, Grabowski CJ. Altered lower esophageal sphincter function during early pregnancy. Gastroenterol. 1978;74(6):1233-7.

9. Guyatt GH, Feeney DH, Patrick DL. Measuring health-related quality of life. Ann Intern Med. 1993;118(8):622-9.

10. Hey VM, Cowely DJ, Ostick DG, Skinner L, Ganguli PC, Cowely DJ. Proceedings: gastroesophageal reflux in late pregnancy. Gut. 1975;16(5):403-4.
11. Knudsen A, Lebech M, Hansen M. Upper gastrointestinal symptoms in the third trimester of the normal pregnancy. Eur J Obstet Gynecol Reprod Biol. 1995;60(1):29-33.

12. Lind JF, Smith AM, McIver DK, Coopland AT, Crispin JS. Heartburn in pregnancy - a manometry study. Can Med Assoc J. 1968;98(12):571-4.

13. Malfertheiner SF, Malfertheiner MV, Kropf S, Costa SD, Malfertheiner P. A prospective longitudinal cohort study: evolution of GERD symptoms during the course of pregnancy. BMC Gastroenterol. 2012;12:2-7.

14. Marrero JM, Goggin PM, Caestecker JS, Pearce JM, Maxwell JD. Determinants of pregnancy heartburn. Br J Obstet Gynaecol. 1992;99(9):731-4.

15. Meyer LC, Peacock JL, Bland JM, Anderson HR. Symptoms and health problems in pregnancy: their association with social factors, smoking, alcohol, caffeine and attitude to pregnancy. Paediatr Perinat Epidemiol. 1994;8(2):145-55.

16. Ramu B, Mohan P, Rajasekaran MS, Jayanthi V. Prevalence and risk factors for gastroesophageal reflux in pregnancy. Indian J Gastroenterol 2011;30(3):144-7.

17. Revicki DA, Wood M, Maton P, Sorensen S. The impact of gastroesophagea reflux disease on health-related quality of life. Am J Med. 1998;104(3):252-8.

18. Vakil N, van Zanten SV, Kahrilas P, Dent J, Jones R, Global Consensus Group. The Montreal definition and classification of gastroesophageal reflux disease: a global evidence-based consensus. Am J Gastroenterol. 2006;101(8):1900-20.

19. Van Thiel DM, Gaveler JS, Joshi SN, Sara RK, Stremple J. Heartburn of pregnancy. Gastroenterology. 1977;72 (4 Pt 1):666-8.

20. Ware JE, Sherbourne CD. The MOS 36 item short-form health survey (SF-36). I. Conceptual framework and item selection. Med Care. 1992;30(6):473-83.

21. Yacavone RF, Locke GR, Provenzale DT, Eisen GM. Quality of life measurement in gastroenterology: What is available? Am J Gastroenterol. 2001;96(2):285-97.

Received 25/9/2014 Accepted 28/11/2014 